\title{
PENGARUH TINGKAT PEMBERIAN PUPUK UREA DAN UMUR PANEN TERHADAP PRODUKSI HIJUAN SORGUM MANIS (Sorghum bicolor (L.) Moench)
}

\author{
Ardian Saputra $^{1)}$, B. Nohong ${ }^{2 * *}$ Rinduwati $^{2)}$ \\ ${ }^{1)}$ Mahasiswa Program Strata Satu Departemen Nutrisi dan Makanan Ternak, \\ Fakultas Peternakan, Universitas Hasanuddin. \\ ${ }^{2)}$ Dosen Departemen Nutrisi dan Makanan Ternak, Fakultas Peternakan, \\ Universitas Hasanuddin. \\ *E-Mail: budiman_ek58@yahoo.com
}

\begin{abstract}
This research was conducted to determine the effect of harvest age and level of urea fertilizer application to the production of sweet sorghum forage. The study was arranged in a completely randomized design with factorial patterns of $2 \times 3$ and three replications. The first factor consists of the age of the harvest, which is 35 days after planting (35 DAP) and 55 days after planting (55 DAP). The second factor is the level of urea fertilizer, which is $0 \mathrm{~kg}$ urea/ha $(0 \mathrm{~g}$ urea/polybag), $150 \mathrm{~kg}$ urea/ha $(0.75 \mathrm{~g}$ urea/polybag) and $250 \mathrm{~kg}$ urea/ha $(1.25 \mathrm{~g}$ urea/polybag). Each treatment unit was given bokashi base fertilizer of 300 $\mathrm{g} /$ polybag each. The results showed that the age of harvest and the level of urea fertilizer affected the production of fresh forages and dry matter of sweet sorghum. There is no interaction between fertilizer level and age of harvest. Production of fresh forages and dried sweet sorghum is higher at a harvest age of 55 days and at the level of fertilizer application of $250 \mathrm{~kg}$ urea/ha $(1.25 \mathrm{~g}$ urea/polybag).
\end{abstract}

Key word: Dry matter production, fresh forage production, urea fertilizer, harvest age

\begin{abstract}
ABSTRAK
Penelitian ini dilakukan untuk mengetahui pengaruh umur panen dan level pemberian pupuk urea terhadap produksi hijauan sorgum manis. Penelitian disusun dalam rancangan acak lengkap pola faktorial 2 × 3 dan tiga kali ulangan. Faktor pertama terdiri atas umur panen, yaitu 35 hari setelah tanam (35 HST) dan 55 hari setelah tanaman (55 HST). Faktor kedua adalah level pupuk urea, yaitu 0 $\mathrm{kg}$ urea/ha (0 g urea/polybag), $150 \mathrm{~kg}$ urea/ha (0,75 g urea/polybag) dan $250 \mathrm{~kg}$ urea/ha $(1,25 \mathrm{~g}$ urea/olybag). Setiap unit perlakuan diberi pupuk dasar bokashi masing-masing $300 \mathrm{~g} /$ polybag. Hasil penelitian menunjukkan bahwa umur panen dan level pemberian pupuk urea berengaruh terhadap produksi hijauan segar dan bahan kering sorgum manis. Tidak ada interaksi antara tingkat pemupukan dengan umur panen. Produksi hijauan segar dan bahan kering sorgum manis lebih tinggi ada umur panen 55 hari dan pada level pemberian pupuk $250 \mathrm{~kg}$ urea/ha (1,25 g urea/olybag).
\end{abstract}

Kata kunci: produksi bahan kering, produksi hijauan segar, Pupuk urea, umur panen, 


\section{PENDAHULUAN}

Sorgum Manis merupakan tanaman asli dari wilayah - wilayah tropis dan subtropis di bagian Pasifik tenggara dan Australia, wilayah yang terdiri dari Australia, Selandia Baru dan Papua. Sorgum merupakan tanaman dari keluarga Poaceae dan marga Sorghum. Sorgum sendiri memiliki 32 spesies. Diantara spesies - spesies tersebut, yang paling banyak dibudidayakan adalah spesies Sorghum bicolor. Tanaman ini sekeluarga dengan tanaman serealia lainnya seperti padi, jagung dan gandum serta tanaman lain seperti bambu dan tebu. Dalam taksonomi, tanaman - tanaman tersebut tergolong dalam satu famili besar Poaceae yang juga sering disebut sebagai Gramineae atau rumput - rumputan (Daru, 2003).

Sorgum merupakan tanaman yang mempunyai banyak kegunaan. Hampir seluruh bagian dari tanaman sorgum seperti biji, tangkai biji, daun, batang dan akar dapat dimanfaatkan. Produk - produk turunan seperti gula, bioetanol, kerajinan tangan, pati, biomas dan lain - lain merupakan beberapa produk yang dapat dihasilkan dari tanaman sorgum. Dari beberapa produk tersebut, produk utama tanaman sorgum adalah biji dan batangnya. Biji sorgum memiliki kandungan tepung dan pati yang sangat potensial. Adapun batang sorgum terutama jenis sorgum manis memiliki kandungan nira sebagaimana halnya tanaman tebu. Nira sorgum dapat digunakan sebagai bahan baku pembuatan gula dan bioetanol (Soeranto, 2002).

Sorgum manis (Sorghum bicolor (L.) Moench) adalah salah satu tanaman serealia yang dapat dikembangkan sebagai bahan pakan, pangan, dan bioetanol. Bagian-bagian tanaman sorgum seperti biji, tangkai biji, daun, batang dan akar dapat dimanfaatkan. Di Indonesia sorgum merupakan tanaman sereal pangan ke tiga setelah padi dan jagung (Nurmala, 2003). Sebagai sumber akan, sorgum dapat dijadikan ransum makanan bagi ternak sebagai pengganti jagung kuning, terutama untuk ayam, karena biji sorgum memiliki harga yang lebih murah daripada jagung kuning sehingga dapat menekan biaya produksi (Tati, 2003). Meskiun sorgum dapat tumbuh pada kurang subur, tetapi untuk mendapatkan hasil yang maksimal diperlukan unsur hara yang untuk membantu 
pertumbuhan tanaman. Karena kebanyakan tanah kekurangan unsur haranitrogen, maka dibutuhkan unsur hara dari luar seperti pupuk urea. Untuk mendapatkan produksi dan kualitas tanaman pakan, maka waktu panen sangat menentukan. Apabila dipanen pada umur yang masih relatif muda, maka produksinya tidak lebih rendah tetapi kualitasnya cukup tinggi. Sebaliknya, jika dipanen pada umur tua, maka produksinya cukup tinggi tetapi kualitasnya rendah. Tujuan penelitian ini adalah untuk mengetahui pengaruh umur panen dan level pemberian pupuk urea terhadap produksi hijauan sorgum

\section{METODE PENELITIAN}

\section{Waktu dan Lokasi Penelitian}

Penelitian ini dilaksakan pada bulan Februari - April 2020, di Laboratorium Lapangan Ilmu Tanaman Pakan dan Pastura, Fakultas Peternakan Universitas Hasanudddin. Penentuan bahan kering dilaksanakan di Laboratorium Kimia Pakan, Fakultas Peternakan Universitas Hasanuddin, Makassar.

\section{Materi Penelitian}

Alat yang digunakan dalam penelitian ini adalah timbangan analitik, kamera, meterandan alat tulis menulis.

Bahan yang digunakan dalam penelitian ini adalah pupuk pupuk urea, bibit (biji) sorgum manis dan polybag ukuran 30x40 cm (kapasitas $10 \mathrm{~kg}$ tanah).

\section{Metode Penelitian}

Penelitian ini meggunakan rancangan acak lengkap (RAL) pola faktorial (Steel dan Torrie, 1993) terdiri yang terdiri dari 2 faktor. Faktor pertama adalah dosis pemupukan nitrogen yang terdiri atas :

$$
\begin{aligned}
& \text { N0 }=\text { kontrol (tanpa pemupukan) } \\
& \text { N1 }=150 \mathrm{~kg} \text { urea } / \mathrm{ha}=0.75 \mathrm{~g} / \text { polybag } \\
& \mathrm{N} 2=250 \mathrm{~kg} \text { urea } / \mathrm{ha}=1.25 \mathrm{~g} / \text { polybag }
\end{aligned}
$$

Faktor kedua adalah umur panen yang terdiri atas:

$\mathrm{U}_{1}=35$ hari setelah tanam (35hst)

$\mathrm{U}_{2}=55$ hari setelah tanam $(55 \mathrm{hst})$ 
Masing-masing perlakuan diulangi 3 (tiga) kali. Kombinasi perlakuan disajikan dalam Tabel 1.

Tabel 1.Kombinasi perlakuan

\begin{tabular}{ccc}
\hline \multirow{2}{*}{ Level puuk } & \multicolumn{2}{c}{ Umur panen $(\mathrm{U})$} \\
\cline { 2 - 3 } No & $\mathrm{U}_{1}=(35 \mathrm{HST})$ & $\mathrm{U}_{2}=(55 \mathrm{HST})$ \\
\hline $\mathrm{U} 1$ & $\mathrm{U}_{1.1} \mathrm{~N}_{0.1}$ & $\mathrm{U}_{2.1} \mathrm{~N}_{0.1}$ \\
& $\mathrm{U}_{1.2} \mathrm{~N}_{0.2}$ & $\mathrm{U}_{2.2} \mathrm{~N}_{0.2}$ \\
& $\mathrm{U}_{1.3} \mathrm{~N}_{0.3}$ & $\mathrm{U}_{2.3} \mathrm{~N}_{0.3}$ \\
\hline $\mathrm{N} 1$ & $\mathrm{U}_{1.1} \mathrm{~N}_{1.1}$ & $\mathrm{U}_{2.1} \mathrm{~N}_{1.1}$ \\
& $\mathrm{U}_{1.2} \mathrm{~N}_{1.2}$ & $\mathrm{U}_{2.2} \mathrm{~N}_{1.2}$ \\
& $\mathrm{U}_{1.3} \mathrm{~N}_{2.3}$ & $\mathrm{U}_{2.3} \mathrm{~N}_{1.3}$ \\
\hline $\mathrm{N} 2$ & $\mathrm{U}_{1.1} \mathrm{~N}_{2.1}$ & $\mathrm{U}_{2.1} \mathrm{~N}_{2.1}$ \\
& $\mathrm{U}_{1.2} \mathrm{~N}_{2.2}$ & $\mathrm{U}_{2.2} \mathrm{~N}_{2.2}$ \\
& $\mathrm{U}_{1.3} \mathrm{~N}_{2.3}$ & $\mathrm{U}_{2.3} \mathrm{~N}_{2.3}$ \\
\hline
\end{tabular}

\section{Persiapan Media Tanam}

Pelaksanaan penelitian dimulai dengan menyiapkan tanah yang akan digunakan. Jenis tanah yang digunakan yaitu tanah ultisol, tanah ini kemudiandigemburkan dan dibersihkan dari batu-batuan dan sisa-sisa tanaman. Tanah kemudian diayak sehingga membentuk tekstur tanah yang seragam. Sebanyak 18 (delapan belas) polybag berukuran 30 x $40 \mathrm{~cm}$ masing-masing diisi dengan tanah seberat $10 \mathrm{~kg}$. Masing-masing polybag ditambahkan bokashi seberat 300 gram sebagai pupuk dasar, kemudian diberi air sampai mencapai kapasitas lapang (persentase kelembaban yang ditahan oleh tanah sesudah terjadinya drainase dan kecepatan gerakan air ke bawah lambat).

\section{Penanaman}

Bibit (biji) yang akan ditanama direndam selama satu malam. Penanaman bibit dilakukan secara langsung dengan menggunakan benih (biji) dengan sistem tuggal, dengan 8-10 benih sorgum per polybag. Setelah tumbuh, kemudian dilakukan penjarangan. Dipilih sebanyak 3 (tiga) tanaman yang tumbuh baik dan seragam untuk dipelihara sebagai bahan penelitian, sedangkan yang lainnya dicabut dan dikeluarkan dari polybag. Pemberian pupuk nitrogen dilakukan pada saat tanaman berumur 2 minggu setelah tanam dengan level 0,75 
g dan 1,25 g/polybag. Tanaman dipeliharan, diberi air secukupnya hingga waktu panen yang ditentukan. Panen pertama dilakukan pada umur 35 hari untuk perlakuan $\mathrm{U}_{1}$ dan panen pada umur 55 hari untuk perlakuan $\mathrm{U}_{2}$.

\section{Parameter yang Diamati}

Parameter yang diamati pada penelitian ini adalah produksi hijauan segar dan produksi bahan kering hijauan sorgum manis.

\section{Pengambilan Data}

Pengambilan data produksi hijauan segar dilakukan dengan memotong tanaman setinggi $5 \mathrm{~cm}$ di atas ermukaan tanah, kemudian ditimbang untuk mendapatkan produksi bahan segarnya.

Produksi bahan kering dilakukan dengan menimbang sampel sebanyak 50 gram setiap unit perlakuan kemudian dikeringkan sampai mencapai berat kosntan untuk mendapatkan bahan keringnya. Persentase bahan kering dihitung menggunakan rumus :

$\% \mathrm{BK}=\frac{\text { Berat kering samel }}{\text { Berat Segar Sampel }} \times 100 \%$

Produksi bahan kering $=\% \mathrm{BK} \times$ Produksi Bahan Segar

Data yang terkumpul dianalisis dengan perangkat lunak statistik SPSS dan diuji lanut dengan Duncans Multiple Range Test (DMRT) pada tingkat probabilitas 5\%.

\section{HASIL DAN PEMBAHASAN}

\section{Produksi bahan segar hijuan}

Produksi hijauan segar tanaman sorgum manis pada umur panen dan level pupuk berbeda disajikan dalam Tabel 2 .

Tabel 2. Produksi bahan segar (g/polybag) hijauan sorgum manis pada umur panen dan level urea berbeda

\begin{tabular}{cccc}
\hline & \multicolumn{2}{c}{ Umur panen $(\mathrm{U})$} & \\
\cline { 2 - 3 } Level puuk & $\mathrm{U}_{1}=(35 \mathrm{HST})$ & $\mathrm{U}_{2}=(55 \mathrm{HST})$ & Jumlah \\
\hline $\mathrm{N} 0$ & 131,75 & 240,00 & $167,83^{\mathrm{b}}$ \\
$\mathrm{N} 1$ & 233,00 & 443,07 & $338,03^{\mathrm{a}}$ \\
$\mathrm{N} 2$ & 262,00 & 572,51 & $469,00^{\mathrm{a}}$ \\
\hline Jumlah & $208,92^{\mathrm{b}}$ & $418,53^{\mathrm{a}}$ & \\
${ }^{\mathrm{ab}}$ Superscrib yang sama pada baris atau kolom yang sama menunjukkan perbedaan nyata \\
$(\mathrm{p}<0.05)$.
\end{tabular}


Sidik ragam menunjukkan bahwa umur panen dan level pemberian pupuk urea berbeda memperlihatkan perbedaan yang nyata $(\mathrm{P}<0,05)$ terhadap produksi bahan segar hijauan segar sorgum manis. Interaksi antara umur panen dengan level pupuk urea tidak berpengaruh nyata $(\mathrm{P}>0,05)$. Uji Duncan menunjukkan bahwa produksi hijauan segar sorgum yang dipanen 55 hari setelah tanam lebih tinggi dibanding dengan umur panen 35 hari setelah tanaman. Hal ini disebabkan karena pada umur panen umur tua (55 hari setelah tanaman) mempunyai waktu yang lebih lama untuk tumbuh, sehingga produksinya lebih tinggi. Hasil penelitian ini sejalan dengan yang dilaporkan oleh Astuti dkk. (2018), bahwa produksi hijauan segar sorgum varietas Numbu yang dipanen pada umur 70 hari setelah tanam menghasilkan hijauan segar lebih tinggi dibanding dengan umur panen 50 dan 60 hari.

Uji Duncan menunjukkan bahwa produksi hijauan segar sorgum yang yang diberi pupuk urea dengan level $150 \mathrm{~kg}$ urea/ha dan $250 \mathrm{~kg}$ urea/ha lebih tinggi dibanding dengan tanpa pupuk. Peningkatan hasil panen ini seiring dengan peningkatan jumlah unsur hara yang diberikan dalam bentuk pupuk. Hasil penelitian ini sejalan dengan yang dilaporkan oleh Ayub et al. (2002), bahwa produksi hijauan segar sorgum yang diberi pupuk nitrogen dengan dosis 50, 100 dan $150 \mathrm{~kg} / \mathrm{ha}$ lebih tinggi dibanding dengan tanpa pupuk (kontrol).

\section{Produksi bahan kering hijauan}

Produksi bahan kering tanaman sorgum manis pada umur panen dan level pupuk berbeda disajikan dalam Tabel 2.

Tabel 3. Produksi bahan kering (g/polybag) hijauan sorgum manis pada umur panen dan level urea berbeda

\begin{tabular}{cccc}
\hline \multirow{2}{*}{ Level puuk } & \multicolumn{2}{c}{ Umur panen (U) } & \\
\cline { 2 - 3 } & $\mathrm{U}_{1}=(35 \mathrm{HST})$ & $\mathrm{U}_{2}=(55 \mathrm{HST})$ & Jumlah \\
\hline No & 14,10 & 38,81 & $22,34^{\mathrm{c}}$ \\
$\mathrm{N} 1$ & 24,79 & 76,18 & $50,48^{\mathrm{b}}$ \\
$\mathrm{N} 2$ & 25,85 & 107,00 & $79,95^{\mathrm{a}}$ \\
\hline Jumlah & $21,58^{\mathrm{b}}$ & $73,99^{\mathrm{a}}$ & \\
\hline abc Superscrib yang sama pada baris atau kolom yang sama menunjukkan perbedaan nyata \\
$(\mathrm{p}<0.05)$.
\end{tabular}


Sidik ragam menunjukkan bahwa umur panen dan level pemberian pupuk urea berbeda memperlihatkan perbedaan yang nyata $(\mathrm{P}<0,05)$ terhadap produksi bahan kering hijauan sorgum manis. Interaksi antara umur panen dengan level pupuk tidak berpengaruh nyata $(\mathrm{P}>0,05)$. Uji Duncan menunjukkan bahwa produksi bahan kering hijauan sorgum yang dipanen 55 hari setelah tanam lebih tinggi dibanding dengan umur panen 35 hari setelah tanaman. Hal ini sejalan dengan laporan Verma et al. (2005) bahwa produksi bahan kering meningkat dengan penundaan panen. Hasil penelitiannya menunjukkan bahwa produksi bahan kering pada (100 hst) lebih tinggi dibanding dengan (75 dan 50 hst). Peningkatan bahan kering ini terjadi karena bertambahnya umur adalah karena lebih banyak pengendapan bahan berserat di bagian tanaman.

Uji Duncan menunjukkan bahwa produksi bahan kering sorgum yang yang diberi pupuk urea dengan level $150 \mathrm{~kg}$ urea/ha dan $250 \mathrm{~kg}$ urea/ha lebih tinggi dibanding dengan tanpa pupuk. Peningkatan produksi bahan kering sorgum seiring dengan peningkatan level nitrogen telah dilaorkan oleh Ayub et al. (2002), Almodares et al. (2009), Saini (2012), Nirmal et al. (2016), Astuti dkk. (2018).

\section{KESIMPULAN}

Produksi hijauan sorgum tertinggi diperoleh pada umur panen 55 hari dan level pupuk urea dengan dosis $250 \mathrm{~kg}$ urea/ha atau $1.25 \mathrm{~g} /$ polybag

\section{DAFTAR PUSTAKA}

Almodares, A., M. Jafarinia and M.R. Hadi. 2009. The Effects of Nitrogen Fertilizer on Chemical Compositions in Corn and Sweet Sorghum. American-Eurasian J. Agric. \& Environ. Sci., 6 (4): 441-446

Astuti, A., Suhartanto, B., Umami, N and A. Agus. 2018. Pengaruh Dosis Pupuk Urea dan Umur Panen Terhadap Hasil Hijauan Sorgum (sorghum bicolor ( L ) Moench. Agrinova: Jurnal of Agriculture Inovation, 1(2):045-051.

Ayub, M., Nadeem, M.A., Tanveer, A and A. Azhar. 2002. Effect of Different Levels of Nitrogen and Harvesting Times on the Growth, Yield and Quality of Sorgum Fodder. Asian Journal of Plant Science. 1(4):304-307.

Daru, M. 2003. Budi daya Rumput Hermada Di Lahan Kering dan Kritis. Kanisius. Yogyakarta 
A. Saputra, B. Nohong, Rinduwati / Buletin Nutrisi dan Makanan Ternak 14(1): 27- 34

Nirmal, S. S., Solanke, A. V., Dudhade, D. D., Shinde, M. S., Gadakh, S. R., Durgude, A. G., \& Damame, S. V. 2016. Response of forage sorghum [Sorghum bicolor (L). Moench] cultivars to nitrogen levels. International Journal of Science, Environment and Technology, 5(4):2605-2609

Nurmala, T. S.W. 2003. Serealia Sumber Karbohidrat Utama. Rineka Cipta. Jakarta.

Saini, A. 2012. Forage Quality of Sorghum (Sorghum bicolor) as Influenced by Irrigation, Nitrogen Level and Harvesting Stage. Indian J. Res. 3(2):6772

Steel, R.G.D and J.H. Torrie. 1993. Prinsip dan Prosedur statistika suatu Pendekatan Biometrik, Jakarta. Terjemahan PT Gramedia.

Sutanto, R. 2002. Penerapan Pertanian Organik Pemasyarakatan dan Pengembangannya. Kanisius. Yogyakarta. 2.

Tati, N.S.W. 2003. Serealia Sumber Karbohidrat Utama. Rineka Cipta. Jakarta.

Verma S. S., Singh N., Joshi Y. P. and Deorari V., 2005. Effect of nitrogen and zinc on growth characters, herbage yield, nutrient uptake and quality of fodder sorghum ( ). Indian J Agron., : 167-169. 